\title{
From Inexperienced Users to Co-creators: An Exploration of a Generative Method
}

\author{
Chrysoula Gatsou \\ Faculty of Fine Arts and Design, TEI of Athens, Athens, Greece \\ cgatsou@teiath.gr
}

\begin{abstract}
One of the main challenges for improving user experience in systems and artifacts lies in how designers, development managers and IT professionals can cultivate empathy in users. The present study offers an empirical example of how inexperienced users can be involved in the early stages of design process. It examines the findings from a generative technique which employs inexperienced users as co-creators in collaboration with the designer, in a collage session during the early design stages of a mobile tablet application centred on the topic of "first aid". The findings of this study identify five ponts for eliciting users' needs. Both designers and practitioners can benefit from such knowledge.
\end{abstract}

Keywords: user experience, generative method, co-design, empathic design, inexperienced user.

\section{Introduction}

The design of artifacts nowadays is more and more complex, since they contain more functions, they make more demands on experience on the part of users and have to take into account various considerations. One of the main challenges for improving user experience in systems and artifacts lies in how designers, development managers and IT professionals can cultivate empathy in users. The increase in mobile communication and personal computing makes additional demands on mobile applications in order that ordinary people perceive technology as beneficial and helpful. Hanington argues that a considerable knowledge of participatory design is vital in broadening the perspective of designers and in illuminating the way in which potential users can contribute creatively to making decisions [8].

Gaver et al. [6] suggest that users should be involved in the design process. They recommend a direct, subjective and empathetic engagement on the part of designers with everyday people, who are normally the main users [6]. Workshop sessions offer designers the opportunity to develop a greater insight into, and understanding of users, so that they can produce more effective designs. Sensitizing designers to the different ways in which individuals complete daily tasks has helped to diminish the gap between users and designers. 
Such approaches are mainly vital to the design of artifacts, because patterns of behaviour, attitudes and personal motivations on the part of users are notable factors in shaping the design and use of artifacts. As a personal, subjective and contextual, in situ method, collaging is often used as a component in generative design research. The collage method itself was inspired by the work of Elizabeth Sanders on generative methods and of Bruce Hanington on innovation methods [7, 20].

The aim of any design is to create new solutions. Design becomes a focusing and generative process, in which interpretations of earlier users' experiences, emerging solutions and the gradual understanding of objectives evolves in the form of a dialogue $[2,13,22]$. The non - specific use of computers and interactive devices began to increase from 1995, whereupon companies recognized the need to acquire a deeper understanding of users. They began to use groups of people possessing different sets of expertise. However, as Preece et al., point out, communication and collaboration among team members is not easy [16]. The reason seems to be that people from various backgrounds have various opinions and various ways of expressing themselves. The lack of a common language creates confusion and becomes a source of resentment and indifference during the exchange of ideas. In the view of Muller, there is a gap between the world of designers and researchers and that of users [15].

\subsection{The Role of Inexperienced User in Design}

According to Gaver et al. and Sanders, users may be engaged in various roles in the development process $[6,21]$. In particular, inexperienced users can be employed as users, testers, informers and design partners. Despite the explosion of technology in mobile communication and personal computing, inexperienced users can feel isolated from this world and a significant divide between expert and inexperienced has arisen. Here we focus mainly on including inexperienced users in the design process as design partners and sources of information. Not all users possess a broad knowledge of interactive technology and may not be able to summarize their unspoken present or future needs in simple terms. It is important to support such people in the design process, because they do not experience interaction with artifacts in the same manner as experts do nor do they have the same insight as experts.

\subsection{Co-creation}

Co - creation draws on innovative ideas generated by users, researchers, designers and stakeholders in general. It redefines how such persons are brought into the process of value creation and engages them in the various experiences generated in the process [17]. Co-creation in design allows ordinary people to exploit their creativity, if they are helped and encouraged to do so. Design should take place in close connection with the context in which the user operates, so that the users move within a familiar environment and any stakeholders involved operate in a context based on real life [1]. The role of users in the design process is changing. Instead of being the passive object of research, they are now seen as active co-designers and co- creators. 


\subsection{The Present Study}

This paper examines the findings drawn from the application of a generative method which employs inexperienced users as co-creators in collaboration with the designer, in a collage session during the early design stages of a mobile tablet application centred around the topic of first aid. This paper opens with a literature review, the aim of which is to establish the theoretical background to our study. The review deals with approaches which exploit the inspirations of users that are triggered by various generative methods. It then describes the research methodology employed. It analyses the data and offers results which are then discussed, before offering some conclusions.

\section{The User Inspiration Approach}

There are a great number of different data-collection methods that can be applied to identify user requirements. Hanington has placed the methods in three main categories: traditional, adaptive and innovative [7]. Innovative methods use creative or participatory tools, such as collages, card sorting, diaries, drama or probes [6,8,18 ]. Innovative methods differ from traditional user-centred design methods, such as surveys and interviews, which give an emphasis to explicit information gathering.

In approaches that require a participatory way of thinking, the user is seen as a collaborator who actively participates in the product design process. This set of approaches focuses on designing in collaboration with users. In the view of Ehn, participatory design is "... design challenge of fully anticipating or envisioning, use before actual use takes place in people's life-worlds." [3]. It also focuses on users' actual, but unexpressed, knowledge, which is usually difficult to assess and describe. Such knowledge thus tends to be ignored by cognitive theory, which has dominated the study of human computer interaction [25]. Participatory design is an emerging practice, which includes non - designers in various activities throughout the planning process. Participatory methods allow all interested parties to contribute directly to the development of an artifact. They allow participants to express themselves directly and actively in the planning process and to identify the needs of the user. Users' behaviors and involvements thus form a framework rooted in everyday life and rest upon emotions and motivations [23]. Thus partipatory design, along with other participatory approaches, goes beyond a number of other design studies and user-centered techniques.

Cultural probes form another technique employed by the user inspiration approach during the design process. The concept of probes was developed by Gaver et al., as a tool for exploring new or better ways of integrating older participants into the everyday life of their communities [6]. Cultural probes were further expanded to facilitate interactions among groups of people in user involvement projects. Research via cultural probes have used cameras, postcards, maps, journals, recording devices, media diaries and various pieces of text and imagery, to elicit personal experiences. Designers thus derive inspiration from the experiences of users and their ideas. In addition, probes give access to participants' everyday lives and personal environment. As Sanders and Dandavate put it, "If we can learn to access people's experiences, we can make user experience the source of inspiration and design"[18]. 
Sanders played an important role in the evolution of participatory product development, in that she proposed the existence of a new approach to design, whereby user involvement should be responsible for the final design [21]. The aim of her research was to improve design through the exploitation of users' experience and she labelled such methods "generative". Such methods help elicit user needs and aid designers in the understanding of user experiences. A new approach therefore “... should facilitate exchange between the people who experience products, interfaces, systems and spaces and the people who design for experiencing" [18]. In the new approach, the role of the designer is to be constructive and to encourage users to express their creativity and decide on their own design [20].

Empathy is a key issue in generative methods. In Wright and McCarthy's view, feelings or empathy are the ability to understand what it feels like to be another person - what that person's situation is like from his/her own perspective [26]. Empathic design is combination of techniques, such as the observation of users or co-creation with them. As Fulton Suri notes, in empathic design designers and researchers over time repeatedly develop and, in dialogue with users themselves, check their understanding in creative terms of users' experiences [4].

Koskinen and Battarbee feel that empathic methods work better in the search for concepts that is the preparation for concept design [11]. Furthermore, Koskinnen considers that designers needed to use systematic ways to study experiences and so recommends direct collaboration between designers and users [10]. On the other hand, Fulton Suri points out that the inner states of the user are the most important factor for designers [5]. She argues that empathic design may not allow a systematic approach to research. Earlier, Leonard and Rayport, in addressing this issue, suggested that designers who exercise empathy through the observation of the environment in which users operate acquire the ability to share the feelings of users and so design artifacts that meet real needs [14]. In a generative research session, users are the creators who generate artifacts in collaboration with the designer/researcher, who simply facilitates the expression of their thoughts and ideas.

\section{Methodology}

\subsection{Participants}

Our session was designed specifically to include a representative pool of potential users of the mobile tablet application. There were twelve participants $(\mathrm{N}=12)$ ranging from 18 to 79 in age (mean age $=41,6, S D=20.9$, years), seven of whom were men and five women. All of the participants had little or no experience in the use of computers. The users' expressions, the designer statements and collaborative activities of the session were videoed by the researcher.

The participants chosen came from various backgrounds, were of various ages and of both sexes (see Table 1). The reasons behind our decision to engage such a variety of people were various. We wished to generate inspiration derived from the experiences of other persons, we wanted our users to contribute to the design of the 
application during the collage session, which meant taking account of various perspectives on a topic, and we wanted to track the course of mutual learning among the participants.

Table 1. Age, gender and number of Participants

\begin{tabular}{l|l|l|l|l|l|l} 
ID & P1 & P2 & P3 & P4 & P5 & P6 \\
\hline Age & 50 & 38 & 26 & 27 & 57 & 79 \\
\hline Gender & M & F & M & F & M & M \\
\hline ID & P7 & P8 & P9 & P10 & P11 & P12 \\
\hline Age & 52 & 31 & 18 & 45 & 65 & 67 \\
\hline Gender & M & M & F & F & F & M
\end{tabular}

\subsection{Procedure}

The study was based on empirical material gathered during the collage session in which inexperienced users were involved in a design process. The aim of the user study was to identify concealed needs on the part of users through an exploration of the experiences of the users in their interactions with tablets in particular. During the study, participants made collages and explained why they made them in the way that they did. Having acquired the tools to express themselves, the participants generated information regarding their personal experiences. This phase began with a discussion in which participants were told of the purpose of the session and of the subject and the process. They then moved on to what Sleeswijk Visser et al. term "sensitizing"[24]. Sensitizing is a process in which participants are energized, encouraged and motivated to think about and explore aspects of their cultural context relating to the topic of the meeting (Fig.1).

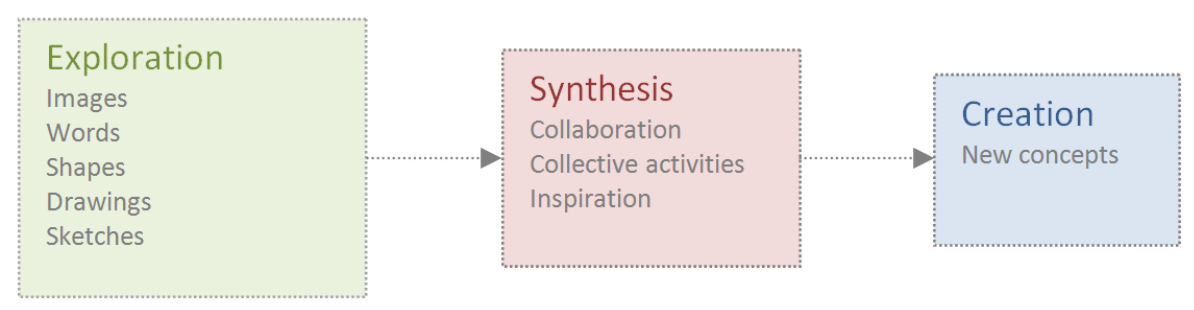

Fig. 1. Conceptual model of the collage session with inexperienced users

Each participant was required to create a collage that expressed the type of expectations and emotions they had regarding a mobile tablet application on the topic of first aid. Participants were required to organize a variety of pictures and words which illustrated the subject of first aid. They were permitted to use paper, crayons, scissors 
and glue to create in whatever way they liked a collage on this theme. Furthermore, they were free to express ideas and questions regarding their collage and pictures. This they did by drawing on insights taken from their social environment and their activities (Fig 2). An elderly user was confused at the beginning and asked if, in addition to using images, he could sketch or draw on the paper. The user was advised to draw or to sketch whatever he wanted in relation to the theme, to express his feelings. Laseau stated "the sketches generated are important because they show how we are thinking about a problem, not just what we think about it" [12]. All participants demonstrated a high level of engagement in this activity.
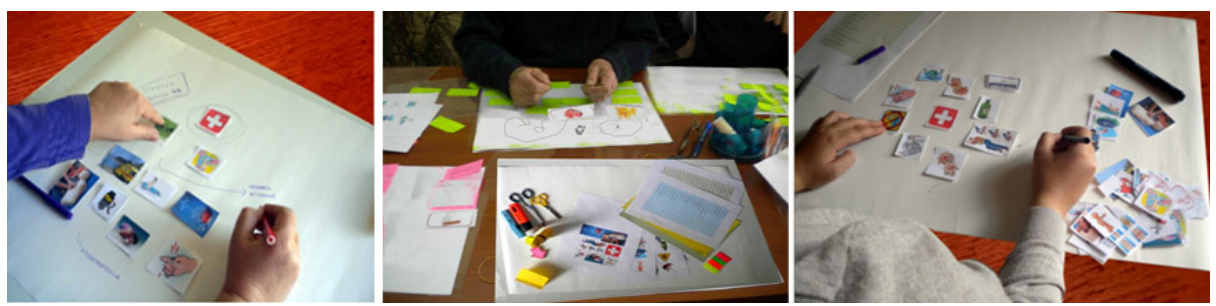

Fig. 2. Participants during the collage session

\section{Results -Discussion}

We interpreted the results in a designerly way, that is, we looked for patterns and exceptions, for the creation of semi-factual stories and attempted to capture appealing design ideas. Any demands for objectivity were left aside [9]. Sanders and William note that methods exist for performing a qualitative and quantitative analysis of data produced by generative methods [19]. The most basic methods focus on determining the factors that appear most often in collage or recordings. Such evidence can serve as a starting point from which one may examine the recordings (i.e., the written record of what was stated by the participants during the session) in the search for recurrent themes and motifs. In the view of Sleeswijk Visser et al., a practical way of extracting information from findings derived from experiential material is to collect carefully selected extracts or instructions from the unprocessed material. Thus ideally the material allows one to interpret the main issues [24].

The summary and combined findings provide a shorter path to the final result, although they represent a map of possible routes and offer an opportunity for the designer to find information and support for his own interpretation and orientation. Various forms of content analysis form an appropriate tool for this. One looks for categories, patterns and themes in the information collected by participants' creations. A simple method is to count the number of times a word or image is used in a collage. The standard procedure of grouping common elements that appear in categories, such as is done in content analysis, is used to identify key issues. In particular, since qualitative research involves samples of smaller size than occurs in a quantitative survey, a large part of the analysis can be done by hand through the use of affinity diagrams [9]. 

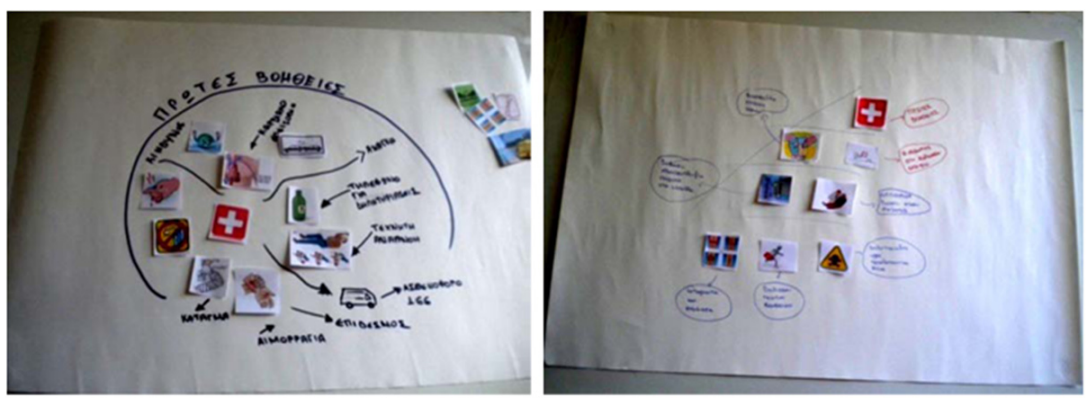

Fig. 3. Participants' posters

The participants generated a total of 14 different design ideas, since some of them created two posters. Analysis of the results showed that "inexperienced users" produced ideas that were more valuable to users. Two design topics became apparent during the session regarding 1) the selection of images preferred by the users and, 2) the way in which users preferred to find information on the topic. The posters offer strong evidence in favour of the effectiveness of convincing design strategies. After the meeting with users, I analyzed the posters in search of design patterns, motifs and surprises (Fig.4) and after the completion of the session I prepared a report on each one of the posters.
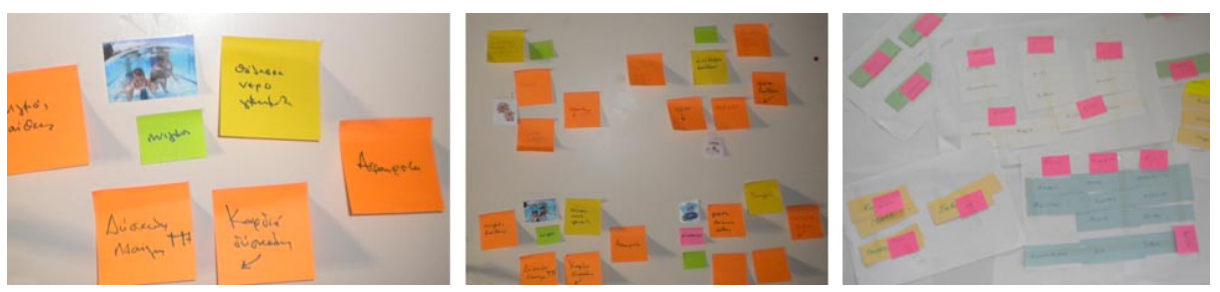

Fig. 4. Analysis of the collage session results

Several issues emerged from participants' ideas, which we subsequently classified in three main categories, namely ideas regarding:

- Icon representation

- The mapping of functions

- Navigation

Our study allowed us to identify five main points required for a successful collage creation session.

- Prepare the collage kit carefully. There should be sufficient images and words, all specific and relevant to the topic of collage. A well-structured session leads to the generation of more creative ideas. 
- Designers, researchers or facilitators should be flexible in their handling of participants.

- One should to listen all the participants. An apparently irrelevant query may produce new insights.

- Preconceptions and stereotypes should be abandoned and participants' ideas should be given full consideration.

- The diversity of participants should be valued.

\section{Conclusions}

The results of the evaluation carried out by designers during collage sessions can contribute to the creation of new ideas and to fruitful speculation and reflection on the designs in question. This paper has also illustrated how a collage session can provide vital information for making such a process possible, because such a session offers a forum for communication between users and designers. Collage seessions also assist in finding solutions that may not have occurred to the researcher. The main fruit of the workshops are the posters that present the design ideas conceived by the users involved. We placed the issues that emerged from the ideas of the participants in three main categories: ideas for icon representation, the mapping of functions and navigation.

In addition, we identify five main points in the structuring of a collage session involving inexperienced users required to produce effective results. We found that the empathic mindset created during the dialogue with users, which includes the kind of informal meetings mentioned above, becomes the key driving force in the interpretation of the materials gathered during the experiment, particularly in regard to matters of design.

One of the conclusions to be derived is that collage sessions need both to be fully integrated into the design process, if they are to act as an effective design tool, and into the practices employed by designers themselves, if they are to contribute to the creation of effective interactive applications.

Acknowledgments. We express our gratitude to the participants, who enthusiastically gave their time to allow us to understand the value of their experiences.

\section{References}

1. Buur, J., Bødker, S.: From usability lab to 'design collaboratorium': reframing usability practice. In: Conference on Designing Interactive Systems, New York, USA (2000)

2. Cross, N.: Designerly ways of knowing. Birkhauser, Boston (2007)

3. Ehn, P.: Participation in design things. In: Proceedings Participatory Design Conference (PDC) Experiences and Challenges, Indiana University, pp. 92-101 (2008)

4. Fulton Suri, J.: Empathic design: Informed and inspired by other people's experience. In: Koskinen, I., Battarbee, K., Mattelmäki, T. (eds.) Empathic Design: User Experience in Product Design, pp. 51-58. Edita IT Press, Helsinki (2003)

5. Fulton Suri, J.: Informing our intuition: Design research for radical innovation. Rotman Magazine, 52-57 (2008) 
6. Gaver, B., Dunne, T., Pacenti, E.: Cultural probes. ACM Interaction 6, 21-29 (1999)

7. Hanington, B.: Methods in the Making: A Perspective on the State of Human Research in Design. Design Issues 19(4), 9-18 (2003)

8. Hanington, B.: Generative Research in Design Education. In: Proceedings of the International Association of Societies of Design Research, IASDR, International Conference, Hong Kong, November 12-15 (2007)

9. Holtzblatt, K., Wendell, J.B., Wood, S.: Rapid contextual design. Morgan Kaufmann, San Francisco (2005)

10. Koskinen, I.: Empathic Design in Methodic Terms. In: Koskinen, I., Battarbee, K., Mattelmäki, T. (eds.) Empathic Design, User Experience in Product Design, pp. 59-65. ITPress, Helsinki (2003)

11. Koskinen, I., Battarbee, K.: Introduction to user experience and empathic design. In: Koskinen, I., Battarbee, K., Mattelmäki, T. (eds.) Empathic Design, User Experience in Product Design, pp. 37-50. IT Press, Helsinki (2003)

12. Laseau, P.: Graphic Thinking For Architects and Designers, 3rd edn. John Wiley and Sons, New York (2001)

13. Lawson, B.R.: How Designers Think, 3rd edn. Architectural Press (1997)

14. Leonard, D., Rayport, J.F.: Spark innovation through empathic design. Harvard Business Review 75(6), 102-113 (1997)

15. Muller, M.J.: Participatory design: The third space in HCI. In: Jacko, J., Sears, A. (eds.) The Human Computer Interaction Handbook: Fundamentals, Evolving Technologies and Emerging Applications, pp. 1051-1068. Lawrence Erlbaum Associates, Mahwah (2002)

16. Preece, J., Rogers, Y., Sharp, H.: Interaction Design: Beyond Human Computer Interaction. John Wiley \& Sons, NY (2002)

17. Ramaswamy, V., Gouillart, F.: The Power of Co-Creation: Build It with Them To Boost Growth, Productivity, and Profits. Free Press (2010)

18. Sanders, E.B.-N., Dandavate, U.: Design for experiencing: New tools. In: O Beeke, C.J., Hekkert, P. (eds.) Proceedings of the First International Conference on Design and Emotion, Delft University of Technology, pp. 87-91 (1999)

19. Sanders, E.B.-N., William, C.T.: Harnessing People's Creativity: Ideation and Expression through Visual Communication. In: Langford, J., McDonagh-Philp, D. (eds.) Focus Groups: Supporting Effective Product Development. Taylor and Francis (2001)

20. Sanders, E.B.-N.: Information, Inspiration and Co-creation. Paper presented at the 6th International Conference of the European Academy of Design, Bremen, Germany (2005)

21. Sanders, E.B.-N.: Design Research in 2006. Design Research Quarterly 1(1), 1-8 (2006)

22. Schön, D.A.: The Reflective Practitioner. How Professionals Think in Action. Basic Books (1983)

23. Schuler and Namioka.: Praticipatory Design: Principles and Practices. Larence Erlbaum, N.J. (1993)

24. Sleeswijk Visser, F., van der Lugt, R., Stappers, P.J.: Participatory design needs participatory communication. In: Proceedings of the 9th European Conference on Creativity and Innovation, Lodz, Poland, pp. 173-195 (2005)

25. Winograd, T., Flores, F.: Understanding Computers and Cognition: A New Foundation for Design. Ablex, Norwood (1986)

26. Wright, P., McCarthy, J.: Empathy and experience in HCI. In: Czerwinski, M., Lund, A., Tan, D. (eds.) Proceedings of the 26th SIGCHI Conference on Human Factors in Computing Systems, pp. 637-646. ACM Press, New York (2008) 